\title{
KARAKTERISTIK HIDROLOGI TANAH DI BAWAH TEGAKAN PINUS (Pinus merkusii), MERAWAN (Hopea odorata Roxb) DAN MAHONI UGANDA (Khaya anthoteca)
}

\author{
Soil Hydrological Characteristics Under Pine (Pinus merkusii), Merawan \\ (Hopea odorata Roxb), and African Mahogany (Khaya anthoteca) Stands
}

\section{Andria Harfani Qalbi1)*, Suria Darma Tarigan²), Enni Dwi Wahjunie ${ }^{2)}$ dan Dwi Putro Tejo Baskoro2)}

\author{
1) Program Studi Ilmu Tanah, Sekolah Pascasarjana, Institut Pertanian Bogor, J1. Meranti Kampus IPB Dramaga, \\ Bogor 16680 \\ 2) Departemen Ilmu Tanah dan Sumberdaya Lahan, Fakultas Pertanian, Institut Pertanian Bogor, Jl. Meranti \\ Kampus IPB Dramaga, Bogor 16680
}

\begin{abstract}
Forest destruction may affect forest hydrological functions either as a water regulator, maintaining the timing and distribution of river water flows, maintaining microclimate, or being able to protect the underlying areas from disasters such as floods. Revegetation is considered as an effort to improve the condition of forest and environment. The objective of this study was to examine the hydrological characteristics of soil under stands of Pinus (Pinus merkusii), Ugandan Mahogany (Khaya anthoteca), and Merawan (Hopea odorata Roxb). The method used is periodic measurement of soil physical variables. Our investigation reveals that hydrological and physical properties of soil under the stands were different. Within the same depth of soil, water content changed from the highest to the lowest in Pine (3.05\%), Merawan Siput Jantan (2.40\%), and African Mahogany (1.89\%), respectively. The highest infiltration was $116.25 \mathrm{~cm}_{\text {hour }}^{-1}$ under Pine stand, while the lowest was $24 \mathrm{~cm}$ hour $r^{-1}$ under Merawan Siput Jantan stand. The highest permeability was $13.27 \mathrm{~cm}_{\text {hour }}{ }^{-1}$ under Pine stand, while the lowest was $2.72 \mathrm{~cm}_{\text {hour }}^{-1}$ under Merawan Siput Jantan stand. Dominated by clay, the soil texture was relatively similar in each stand. Further, the soil under the three stands were categorized as the soil hydrological group B.
\end{abstract}

Keywords: Infiltration, permeability, soil moisture, tree stand

\section{ABSTRAK}

Kerusakan hutan dapat mempengaruhi fungsi hidrologi hutan sebagai pengatur tata air, menjaga waktu dan penyebaran aliran air sungai, menjaga iklim mikro, dan melindungi daerah di bawahnya dari berbagai bencana seperti banjir. Penanaman pohon kembali dinilai merupakan salah satu upaya untuk memperbaiki kondisi hutan dan lingkungan. Tujuan penelitian ini adalah untuk mengkaji karakteristik hidrologi tanah di bawah tegakan tanaman Pinus (Pinus merkusii), Mahoni Uganda (Khaya anthoteca), dan Merawan (Hopea odorata Roxb). Metoda yang digunakan adalah pengukuran sifat-sifat fisik tanah secara periodik. Hasil penelitian ini menunjukkan perbedaan karakterisitik kadar air, infiltrasi dan permeabilitas pada berbagai tegakan pohon. Perubahan kadar air tertinggi terjadi pada tanah di bawah Pinus sebesar 3.05\%, Merawan sebesar 2.40\%, dan terendah pada Mahoni Uganda sebesar $1.89 \%$ pada kedalaman tanah yang sama. Infiltrasi tertinggi sebesar $116.25 \mathrm{~cm}^{-1} \mathrm{~mm}^{-1}$ di bawah

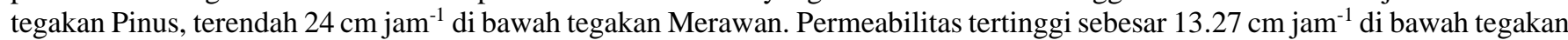
Pinus, terendah di bawah tegakan merawan sebesar $2.72 \mathrm{~cm} \mathrm{jam}^{-1}$. Tekstur tanah relatif sama pada masing-masing tegakan yakni didominasi oleh liat. Tanah di bawah tegakan tanaman Pinus, Merawan dan Mahoni Uganda termasuk kelompok hidrologi tanah B.

Kata kunci: Infiltrasi, permeabilitas, kelembaban tanah, tegakan pohon

\section{PENDAHULUAN}

Indonesia merupakan negara dengan iklim tropis. Sebagai negara tropis Indonesia memiliki permasalahan hidrologi yakni banjir di musim hujan dan kekeringan di musim kemarau. Berbagai bencana hidrologis seperti banjir dan kekeringan yang terjadi di Indonesia tidak lepas dari kerusakan sumberdaya hutan (Tarigan dan Widyaliza, 2015; Tarigan, 2016).

Kerusakan hutan yang terjadi dapat mempengaruhi fungsi hidrologi hutan, yakni sebagai pengatur tata air, menjaga iklim mikro, menjaga waktu penyebaran aliran air sungai dan mampu melindungi daerah di bawahnya dari berbagai bencana seperti banjir (Asdak, 1995; Junaidi dan Tarigan, 2011; Tarigan et al., 2016). Menurut data Kementerian Kehutanan (2013), sekitar $68.6 \%$ dari total luas daratan Indonesia merupakan kawasan hutan, sehingga menjadi salah satu potensi sumber daya alam sekaligus rawan terjadi kerusakan karena kepentingan manusia dalam memenuhi kebutuhan hidupnya. Faktor penyebab terjadinya kerusakan hutan di Indonesia pada umumnya disebabkan oleh pembalakan liar, kebakaran hutan, dan deforestasi. 
Penanaman pohon kembali dinilai sebagai salah satu upaya untuk memperbaiki kondisi hutan dan lingkungan. Fungsi pohon sebagai vegetasi hutan dalam memperbaiki kondisi hutan terjadi melalui perlindungannya terhadap permukaan tanah dari hempasan energi kinetik air hujan, yakni melalui tajuk (kanopi) serasah serta perbaikan pori-pori tanah. Pohon mempunyai tajuk yang mampu menahan hempasan energi kinetik air hujan, serasah menutupi permukaan tanah sehingga melindungi permukaan tanah, sementara melalui sistem perakaran mampu memperbaiki porositas tanah dan infiltrasi tanah (Sunarti et al., 2008).

Informasi mengenai karakteristik hidrologi tanah di bawah tegakan tanaman seperti nilai evapotranspirasi, infiltrasi dan kadar air tanah dari berbagai jenis tegakan tanaman belum semuanya tersaji. Padahal nilai evapotranspirasi setiap tanaman berbeda. Linsley dan Franzini (1985) menyatakan, ada 3 faktor yang mendukung kecepatan evapotranspirasi, yaitu: (1) faktor iklim mikro yang mencakup: radiasi netto, suhu, kelembaban dan angin, (2) faktor tanaman yang mencakup: jenis tanaman, derajat penutupannya, struktur tanaman, stadia perkembangan sampai masak, keteraturan dan banyaknya stomata, mekanisme menutup dan membukanya stomata, (3) faktor tanah yang mencakup: kondisi tanah, aerasi tanah, potensial air tanah dan kecepatan air tanah bergerak ke akar tanaman.

Selain mempengaruhi nilai evapotranspirasi perbedaan jenis tanaman juga mempengaruhi kondisi tanah di bawah tegakannya. Jumlah hasil serasah yang dihasikan juga akan mempengaruhi kondisi tanah di bawahnya. Serasah merupakan sumber humus yang akan membentuk bahan organik. Bahan organik dapat meningkatkan kapasitas air tanah. Hasil serasah tanaman juga akan menutup tanah di bawah tegakkannnya, semakin tertutup tanah akan mengurangi energi kinetik air hujan.

Tanaman Pinus (Pinus merkusii) merupakan salah satu jenis tanaman yang banyak dipakai sebagai tanaman reboisasi. Potensi ekonomi tanaman pinus cukup tinggi karena tidak hanya hasil kayu yang dapat dimanfaatkan tapi juga buah dan getahnya. Hal ini pula yang menjadikan tanaman ini diminati sebagai tanaman reboisasi. Namun di beberapa daerah dilaporkan adanya dampak negatif dari penanaman pohon pinus yakni terjadinya penurunan atau berkurangnya sumber mata air di sekitar kawasan pinus. Oleh karena itu, diperlukan informasi ilmiah mengenai karakteristik hidrologi di bawah tegakan pinus agar dapat menjawab permasalahan ini. Priyono dan Sadhardjo (2002) menyatakan beberapa lokasi dijumpai adanya reboisasi hutan pinus yang berhasil, tetapi justru hasil air menjadi berkurang karena terjadi defisit air di kawasan hutan pinus.

Tanaman Khaya anthoteca atau dikenal juga dengan Mahoni Uganda merupakan salah satu tanaman yang dikembangkan oleh Balai Penyelidikan Kehutanan sejak 1937 di 14 hutan penelitian di Jawa. Tanaman ini dinilai mampu beradaptasi dengan iklim Indonesia (Mindawati dan Tiryana, 2002). Tanaman ini memiliki serat yang lurus dan agak kasar dengan tekstur seragam sehingga banyak dijadikan sebagai bahan mebel mewah, vinir dekoratif, bahan ukiran atau kayu pelapis yang eksotis. Harga kayu ini tergolong tinggi yakni sekitar Rp. 2.9 juta sampai Rp. 4.42 juta $\mathrm{m}^{-3}$. Melihat tingginya potensi tanaman ini mulai banyak diminati untuk ditanam, bahkan Perhutani (Perusahaan Hutan Negara Indonesia) sudah mengembangkannya di daerah pantai selatan Jawa sejak tahun 2000. Akan tetapi informasi ilmiah mengenai karakteristik hidrologi tanah di bawah tegakan Mahoni Uganda masih belum memadai. Informasi ini sangat dibutuhkan agar menghindari terjadinya permasalahan hidrologis pada kawasan yang ditanami pohon tersebut.

Oleh karena itu, informasi mengenai karakteristik hidrologi tanah di bawah tegakan berbagai jenis tanaman mutlak diperlukan demi tercapai upaya perbaikan kondisi lingkungan dan hidrologi tanah yang tepat serta mampu memberikan nilai ekonomi yang tinggi seperti tanaman Pinus (Pinus merkusii), Mahoni Uganda (Khaya anthoteca), dan Merawan (Hopea odorata Roxb). Penelitian ini bertujuan mengkaji karakteristik hidrologi tanah di bawah tegakan tanaman Pinus (Pinus merkusii), Mahoni Uganda (Khaya anthoteca), dan Merawan (Hopea odorata Roxb).

\section{BAHAN DAN METODE}

\section{Lokasi dan Waktu Penelitian}

Penelitian dilakukan di kawasan Hutan Penelitian Dramaga Bogor milik Pusat Penelitian dan Pengembangan Konservasi dan Rehabilitasi Kementerian Kehutanan Republik Indonesia. Secara administratif Hutan Penelitian Dramaga termasuk dalam area Desa Situ Gede dan Desa Bubulak, Kecamatan Bogor Barat, Kota Bogor, Provinsi Jawa Barat berada pada ketinggian $220 \mathrm{~m}$ di atas permukaan laut dengan koordinat 6³3'7.43" LS; 10645'3.25" BT. Pengujian dilakukan di Laboratorium Departemen Ilmu Tanah dan Sumberdaya Lahan, Fakultas Pertanian, Institut Pertanian Bogor. Penelitian dilaksanakan pada bulan April 2015 sampai Januari 2016.

\section{Bahan dan Peralatan Penelitian}

Bahan dan alat yang digunakan dalam penelitian ini terdiri dari air untuk pengukuran infiltrasi, double ring infiltrometer, penggaris, bor tanah, bor kada air tanah, ring sampel, stopwatch, ember, gayung, tali rafia, balok kayu, palu, kantong plastik, kertas label, karet gelang, gunting, alat tulisdan corong. Serta bahan dan alat yang dibutuhkan dalam pengukuran sifat-sifat tanah di laboratorium yaitu cawan, timbangan, oven, dan alat pengukuran permeabilitas.

\section{Metode Penelitian}

\section{Penentuan Plot Sampel Lokasi Penelitian}

Plot penelitian ditentukan dengan metode nested sampling dengan memperhatikan faktor lingkungan seperti kemiringan dan jenis tanah sama. Hutan Penelitian Dramaga memiliki kelompok-kelompok pohon dengan jenis yang berbeda dengan umur hampir seragam serta berada pada jenis tanah yang sama yakni latosol cokelat kemerahan (Departemen Kehutanan, 1994). Kemudian dipilih 3 jenis kelompok pohon di Hutan Penelitian Dramaga sebagai objek pengamatan, yakni Pinus (Pinus merkusii) umur 55 tahun, Mahoni Uganda (Khaya anthoteca) 58 tahun. Setiap plot terdiri dari satu pohon dan masing-masing diulang empat kali atau empat pohon untuk satu jenis kelompok pohon. 
Pengambilan sampel tanah dilakukan pada masing-masing tanah di bawah tegakan tanaman Pinus (Pinus merkusii), Mahoni Uganda (Khaya anthoteca) dan Merawan (Hopea odorata Roxb). Setiap sampel tanah diambil pada pertengahan tajuk (A) dan ujung tajuk (B) masing-masing pohon (Gambar 1), sehingga ada 24 sampel. Masing-masing sampel diberi tanda $\mathrm{P}$ (Pinus), K (Mahoni Uganda) dan H (Merawan).

\section{Variabel yang Diamati}

Variabel yang diamati pada penelitian ini adalah kadar air, permeabilitas dan infiltrasi tanah. Pengambilan sampel tanah untuk pengukuran kadar air dilakukan setiap hari selama 16 hari berturut-turut pada siang hari atau pukul 13.00 WIB menggunakan bor tanah. Pengambilan sampel tanah dilakukan pada kedalaman 0-30 cm dan 30-60 cm. Pengukuran permeabilitas tanah menggunakan ring sampel yang diambil pada kedalaman 0-30 cm dan 30-60 cm. Pengukuran dilakukan di laboratorium. Pengukuran infiltrasi dilakukan di lapang dengan menggunakan double ring infiltrometer

Pengukuran kadar air tanah di laboratorium menggunakan metode gravimetrik, permeabilitas menggunakan metoda Constant Head Permeameter dan infiltrasi di lapangan menggunakan metoda double ring infiltrometer.

\section{Analisis Data}

Rancangan percobaan yang dipakai adalah nested sampling, dimana ulangan dan posisi sampling (di tengah dan ujung tajuk) dibuat nested dalam jenis pohon. Data hasil pengamatan diolah secara statistik menggunakan Analysis of Varian (Anova) dan uji lanjut Duncan. Anova pada penelitian ini digunakan untuk mengetahui pengaruh jenis tanaman terhadap karakteristik hidrologi tanah. Faktor yang berpengaruh terhadap karakteristik hidrologi tanah diuji lanjut menggunakan uji Duncan. Uji Duncan digunakan untuk melihat faktor yang memiliki nilai berbeda nyata pada taraf $5 \%(\alpha=0.05)$.

\section{HASIL DAN PEMBAHASAN}

\section{Keadaan Umum Lokasi Penelitian}

Menurut peta tanah tinjau propinsi Jawa Barat (Puslittanak, 1966) dengan skala 1:25,000 tanah didaerah ini termasuk jenis latosol kemerah-merahan dengan bahan induk tuf vulkan intermedier dengan fisiografi vulkan. Hutan Penelitian Dramaga bertopografi datar sampai bergelombang ringan. Rata-rata curah hujan setahun di daerah ini 3,552 $\mathrm{mm}$ dan hari hujan 187. Rata-rata temperatur maksimum adalah $30.1{ }^{0} \mathrm{C}$ dan rata-rata temperatur minimum adalah $20.1{ }^{\circ} \mathrm{C}$.
Hutan Penelitian Dramaga terbagi atas 233 petak dengan luas tiap petak sebesar $250 \mathrm{~m}^{2}$, setiap petak ditanami jenis-jenis tanaman tahunan/kehutanan tertentu. Penanaman pertama dilakukan tahun 1956 dan saat ini terdapat 123 jenis dari tanaman kehutanan 39 famili dan 80 genus.

\section{Kadar Air Tanah}

Secara umum kadar air di bawah tegakan Pinus, Merawan, dan Mahoni Uganda relatif stabil, mulai dari hari pertama sampai pada pengukuran hari keenam belas (Gambar 2). Kehilangan air pada permukaan tanah di bawah tegakan tegakan Pinus, Merawan, dan Mahoni Uganda kecil karena kondisi tegakan tanaman memiliki tajuk sebagai penutup tanah yang rapat.

Perubahan kadar air tertinggi pada kedalaman tanah $30 \mathrm{~cm}$ di tengah tajuk terjadi di bawah tegakan Pinus sebesar $3.05 \%$, Merawan sebesar $2.40 \%$, dan terendah pada Mahoni Uganda sebesar $1.89 \%$. Hal ini menunjukkan bahwa Pinus mengalami evapotranspirasi yang relatif lebih tinggi dibanding tanaman lainnya. Salah satu penyebab penurunan kadar air tanah adalah evapotranspirasi. Menurut Tanner (1981) kehilangan air melalui evaporasi mempunyai akibat terhadap fisiologi tanaman secara tidak langsung, seperti mempercepat penurunan kadar air pada lapisan atas. Tanah pada kawasan Pinus, Merawan maupun Mahoni Uganda secara keseluruhan memiliki nilai kadar air tanah terendah pada kedalaman $30 \mathrm{~cm}$ di tengah tajuk (A1) (Gambar 2). Ini menunjukkan bahwa kehilangan air tanah semakin tinggi pada lapisan atas di tengah tajuk akibat serapan air oleh akar tanaman tinggi. Semakin dekat dengan jarak tanaman semakin banyak air yang dapat diserap oleh akar melalui proses transpirasi.

\section{Permeabilitas}

Hasil analisis statistik menunjukkan bahwa permeabilitas tanah di bawah tegakan Pinus, Merawan, dan Mahoni Uganda tidak berbeda nyata (Tabel 1). Hal ini terjadi karena tekstur tanah dan kadar bahan organik di bawah tegakan Pinus, Merawan dan Mahoni Uganda relatif sama.

Faktor yang mempengaruhi permeabilitas tanah adalah tekstur tanah dan kadar bahan organik tanah. Tekstur tanah adalah perbandingan relatif (dalam bentuk persentase) fraksi-fraksi pasir, debu dan liat. Partikelpartikel pasir memiliki luas permukaan yang kecil dibandingkan debu dan liat tetapi ukurannya besar. Semakin banyak ruang pori diantara partikel tanah semakin dapat memperlancar gerakan udara dan air didalam tanah. Luas permukaan debu jauh lebih besar dari permukaan pasir dengan tingkat pelapukan dan pembebasan unsur hara untuk diserap akar lebih besar dari pasir. Tanah yang memiliki kemampuan besar dalam memegang air adalah fraksi liat (Hanafiah, 2005; Baskoro dan Tarigan, 2007). 


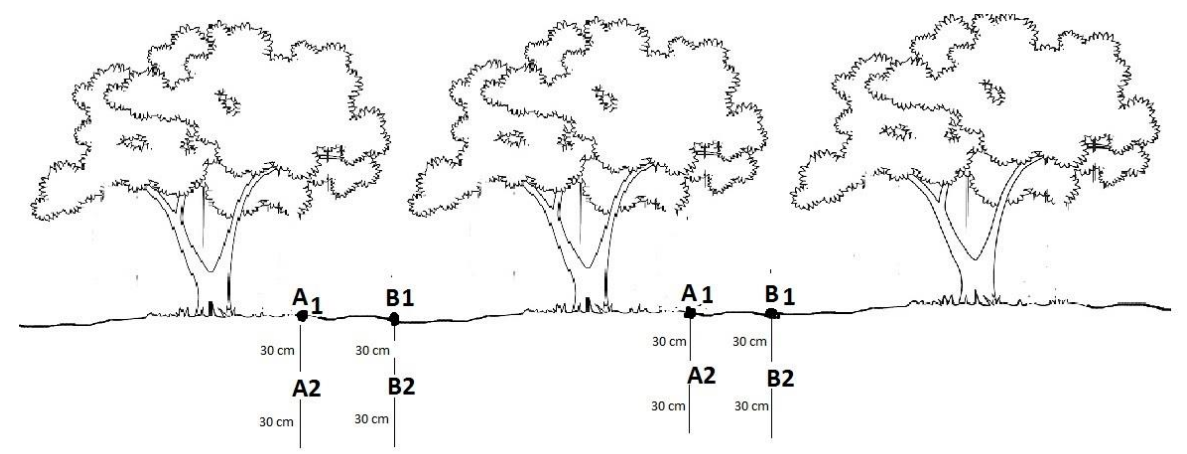

Keterangan: $\quad$ Al= Tengah tajuk Tanaman kedalaman $0-30 \mathrm{~cm}$

A2 = Tengah tajuk tanaman kedalaman $30-60 \mathrm{~cm}$

$B 1=$ Ujung tajuk Tanaman kedalaman $0-30 \mathrm{~cm}$

$B 2=$ Ujung tajuk tanaman kedalaman $30-60 \mathrm{~cm}$

Gambar 1. Ilustrasi titik sampling

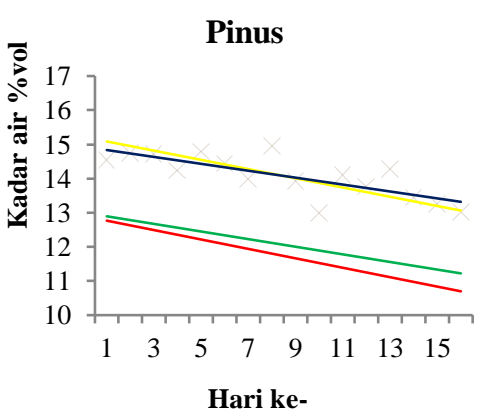

Hari ke-

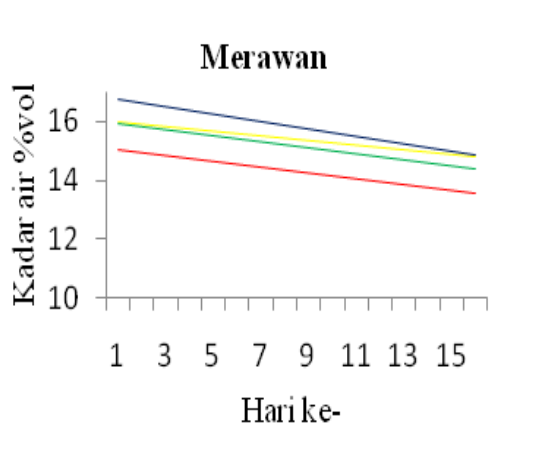

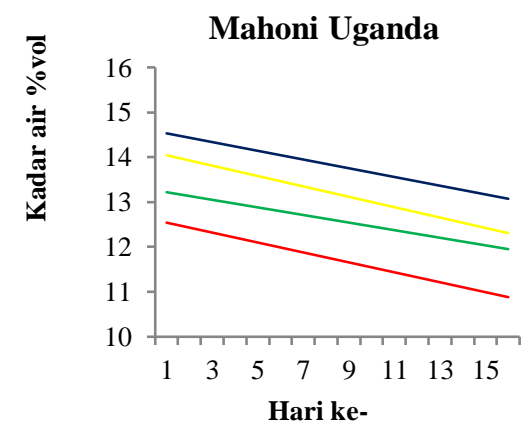

Keterangan:

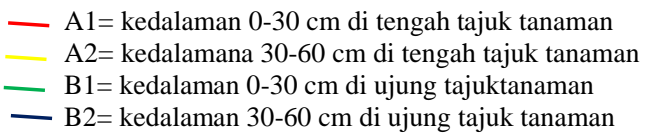

Gambar 2. Kadar air \% di bawah tegakan Pinus, Merawan, dan Mahoni Uganda.

Tabel 1. Permeabilitas tanah di bawah tegakan tanaman Pinus (Pinusmerkusii), Mahoni Uganda (Khaya anthoteca) dan Merawan (Hopea odorata Roxb)

\begin{tabular}{|c|c|c|c|c|}
\hline $\begin{array}{l}\text { Posisi dan } \\
\text { kedalaman }\end{array}$ & $\begin{array}{c}\text { Pinus } \\
\text { Merkusii }\end{array}$ & $\begin{array}{c}\text { Hopea } \\
\text { Odorata Roxb }\end{array}$ & $\begin{array}{c}\text { Khaya } \\
\text { Anthoteca }\end{array}$ & Rataan \\
\hline & \multicolumn{4}{|c|}{$\ldots . \mathrm{cm} \mathrm{jam}^{-1} \ldots$} \\
\hline A1 & 13.20 & 13.19 & 13.06 & $13.15 \mathrm{a}$ \\
\hline A2 & 4.69 & 2.72 & 4.56 & $3.99 b$ \\
\hline B1 & 13.27 & 12.82 & 12.76 & $12.95 \mathrm{a}$ \\
\hline B2 & 5.79 & 3.69 & 4.52 & $4.67 \mathrm{~b}$ \\
\hline Rataan & $9.24 \mathrm{p}$ & $8.10 \mathrm{p}$ & $8.72 \mathrm{p}$ & \\
\hline \multicolumn{5}{|c|}{$\begin{aligned} \text { Keterangan: angka yang diikuti oleh huruf sama pada ni } \\
\text { tidak berbeda nyata menurut uji Duncan pada } \\
(\alpha=0.05) \\
\begin{aligned} & A 1= \text { Tengah tajuk Tanaman kedalaman } 0-30 \mathrm{~cm} \\
& A 2= \text { Tengah tajuk tanaman kedalaman } 30-60 \mathrm{~cm} \\
& B 1= \text { Ujung tajuk Tanaman kedalaman } 0-30 \mathrm{~cm} \\
& \text { B2 }=\text { Ujung tajuk tanaman kedalaman } 30-60 \mathrm{~cm}\end{aligned}\end{aligned}$} \\
\hline
\end{tabular}

Dari Tabel 1 dapat diketahui bahwa nilai permeabilitas tertinggi terdapat pada tanah di bawah tegakan Pinus yakni sebesar $13.27 \mathrm{~cm} \mathrm{jam}^{-1}$ pada kedalaman $30 \mathrm{~cm}$ di ujung tajuk tanaman dan terendah pada tanaman Merawan sebesar $2.72 \mathrm{~cm} \mathrm{jam}^{-1}$ pada kedalaman $60 \mathrm{~cm}$ di tengah tajuk tanaman. Semakin kedalam tanah nilai permeabilitas semakin kecil. Tanah pada lapisan atas memiliki nilai porositas tanah yang lebih tinggi dibandingkan dengan tanah lapisan bawah serta nilai berat volume yang lebih rendah dibandingkan dengan lapisan bawah. Porositas atau ruang pori adalah rongga antar tanah yang biasanya diisi air atau udara. Pori sangat menentukan dalam permeabilitas tanah. Semakin besar pori dalam tanah tersebut, maka semakin cepat permeabilitas tanah tersebut (Hanafiah, 2005). Dengan demikian nilai permeabilitas cenderung menurun dengan kedalaman tanah.

\section{Infiltrasi}

Hasil analisis statistik menunjukkan bahwa infiltrasi di bawah tegakan Pinus nyata lebih tinggi yakni sebesar $116.25 \mathrm{~cm} \mathrm{jam}^{-1}$ dibanding Merawan dan Mahoni Uganda. Sementara infiltrasi di bawah tegakan Mahoni Uganda dan Merawan tidak berbeda nyata (Tabel 2). Infiltrasi tertinggi terdapat pada tanah di tengah tajuk di bawah tegakan Pinus dan terendah pada tanah di bawah tegakan Merawan yakni sebesar $24 \mathrm{~cm} \mathrm{jam}^{-1}$ di ujung tajuk tanaman.

Perbedaan besarnya infiltrasi sangat ditentukan oleh penutupan tanah oleh vegetasi dan tajuk, faktor fisik tanah, serta aktivitas biologi. Tingginya infiltrasi pada tanah di bawah tegakan Pinus dibandingkan dengan infiltrasi tanah di bawah tegakan Mahoni Uganda dan Merawan disebabkan oleh faktor sifat fisik tanah seperti nilai permeabilitas. Permeabilitas tanah di bawah tegakan Pinus 
lebih tinggi dibanding tanah di bawah tegakan tanaman lainnya. Semakin tinggi permeabilitas semakin tinggi pula infiltrasi tanah (Plaster, 2003). Selain itu jumlah fraksi pasir pada tanah di bawah tegakan Pinus relatif lebih tinggi dibandingkan dengan tanah di bawah tegakan tanaman lainnya, sedangkan antara Merawan dan Mahoni Uganda memiliki fraksi pasir yang relatif sama. Tanah di bawah tegakan Pinus memiliki fraksi pasir sebesar 14.04\%, sementara di bawah tegakan Merawan $4.87 \%$ dan di bawah tegakan Mahoni Uganda sebesar 5.63\%. Tanah yang bertekstur pasir mempunyai proporsi pori makro yang lebih besar, sedangkan tanah-tanah bertekstur liat didominasi oleh pori-pori mikro. Pori tanah yang berukuran makro lebih berperan dalam proses pertukaran air dan udara di dalam tanah dibandingkan dengan pori tanah yang berukuran mikro (Baver et al., 1972). Tingginya infiltrasi di bawah tegakan Pinus dipengaruhi adanya jumlah serasah yang tinggi di atas permukaan tanah. Tingginya tumpukan serasah dapat menjadi sarang atau tempat hidup serangga, ini akan berdampak pada aktivitas mikroorganisme. Asdak (1995) menyatakan bahwa aktivitas biologi seperti aktivitas akar tanaman dan organisme mempengaruhi pembentukan agregat tanah. Banyaknya perakaran meningkatkan granulasi dan aktivitas mikroorganisme yang pada akhirnya meningkatkan porositas tanah dan kestabilan struktur tanah. Sistem perakaran dan serasah yang dihasilkan dapat membantu meningkatkan permeabilitas tanah dan laju infiltrasi

Tabel 2. Infiltrasi di bawah tegakan Pinus (Pinusmerkusii), Mahoni Uganda (Khaya anthoteca), dan Merawan (Hopea odorata Roxb)

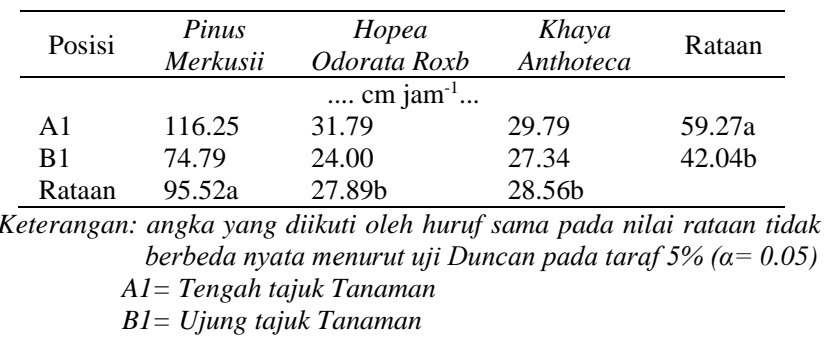

Nilai infiltrasi menurun mulai dari tengah tajuk tanaman sampai ujung tajuk tanaman (Tabel 2). Penurunan ini terjadi karena adanya pengaruh tutupan tajuk yang lebih rapat dan aktivitas akar tanaman yang lebih banyak di tengah tajuk. Rahim (2003) menyatakan bahwa peranan penting dari tanaman adalah melindungi tanah dari pukulan hujan secara langsung dengan jalan mematahkan energi kinetiknya melalui tajuk, ranting dan batangnya. Serasah yang jatuh dan menumpuk akan membentuk humus yang berguna untuk menaikkan kapasitas infiltrasi tanah.

\section{Kelompok Hidrologi Tanah}

Penentuan kelompok hidrologi tanah pada penelitian ini dilakukan berdasarkan data permeabilitas (Tabel 1). Menurut USDA (2009), jika data permeabilitas tersedia dan dianggap dapat diandalkan, maka data ini dapat digunakan untuk menggolongkan tanah tersebut ke dalam kelompok hidrologi tanah yang sesuai. Berdasarkan klasifikasi USDA (2009), tanah di bawah tegakan Pinus, Merawan, dan Mahoni Uganda yang memiliki permeabilitas mulai dari $2.72 \mathrm{~cm} \mathrm{jam}^{-1}$ sampai $13.27 \mathrm{~cm}$ jam $^{-1}$, dapat dikelompokkan pada kelompok hidrologi tanah B. Kelompok hidrologi tanah pada penelitian ini berada pada kelompok yang sama. Hal ini disebabkan nilai permeabilitas tanah pada dimasing-masing tegakan tidak berbeda nyata. Tanah pada kelompok hidrologi tanah B, memiliki potensi limpasan cukup rendah bila benar-benar basah dan transmisi air melalui tanah tanpa hambatan. Informasi mengenai kelompok hidrologi tanah ini diperlukan dalam pendugaan aliran permukaan dan erosi tanah.

\section{SIMPULAN}

Hasil penelitian ini menunjukkan nilai karakteristik hidrologi tanah yang berbeda di bawah tegakan Pinus, Merawan dan Mahoni Uganda. Perubahan kadar air tertinggi terjadi pada tanah di bawah tegakan Pinus sebesar $3.05 \%$, Merawan sebesar $2.40 \%$ dan terendah pada tanah di bawah tegakan Mahoni Uganda sebesar $1.89 \%$. Infiltrasi tertinggi terdapat pada tanah di bawah tegakan Pinus yakni sebesar $116.25 \mathrm{~cm} \mathrm{jam}^{-1}$ di tengah tajuk tanaman, terendah pada tanah di bawah tegakan Merawan yakni sebesar $24 \mathrm{~cm} \mathrm{jam}^{-1}$ di ujung tajuk tanaman. Infiltrasi di bawah tegakan Pinus berbeda nyata dengan Mahoni Uganda dan Merawan. Sementara infiltrasi di bawah tegakan Mahoni Uganda dan Merawan tidak berbeda nyata. Infiltrasi di bawah tegakan berbeda nyata terhadap posisi tajuk tanaman. Permeabilitas tertinggi terdapat pada tanah di bawah tegakan Pinus yakni sebesar $13.27 \mathrm{~cm} \mathrm{jam}^{-1}$ pada kedalaman $30 \mathrm{~cm}$ di ujung tajuk tanaman dan terendah sebesar $2.72 \mathrm{~cm} \mathrm{jam}^{-1}$ pada tanah di bawah tegakan Merawan dengan kedalaman $60 \mathrm{~cm}$ di tengah tajuk tanaman. Tanah di bawah tegakan Pinus, Merawan dan Mahoni Uganda berada pada kelompok hidrologi tanah yang sama yakni kelompok hidrologi tanah B.

\section{DAFTAR PUSTAKA}

Asdak, C. 1995. Hidrologi dan Pengelolaan Daerah Aliran Sungai. Gadjah Mada University Press., Yogyakarta.

Baskoro, D.P.T. dan S.D. Tarigan. 2007. Soil moisture characteristics on several soil types. Jurnal Tanah dan Lingkungan, 9:77-81.

Baver, L.D., W.H. Gardner and W.R. Gardner. 1972. Soil Physics. Jhon Wiley and Sons Inc., New York.

Departemen Kehutanan. 1994. Kebun Percobaan Dramaga (Edisi Pertama). Badan Penelitian dan Pengembangan Kehutanan, Departemen Kehutanan Indonesia, Jakarta.

Hanafiah, K.A. 2005. Dasar-Dasar Ilmu Tanah. PT Raja Grafindo Persada, Jakarta.

Junaidi, E. dan S.D. Tarigan. 2011. Pengaruh hutan dalam pengaturan tata air dan proses sedimentasi Daerah Aliran Sungai (DAS): Studi Kasus di DAS Cisadane. Jurnal Penelitian Hutan dan Konservasi Alam, 8:155-176. 
Karakteristik Hidrologi Tanah di Bawah Tegakan Pinus, Mahoni Uganda, dan Merawan (Qalbi, A.H., S.D. Tarigan, E.D. Wahjunie dan D.P.T. Baskoro)

Kementerian Kehutanan. 2013. Statistik Kehutanan Indonesia 2012. Kementerian Republik Indonesia, Jakarta.

Linsley, R.K. and B.J. Franzini. 1985. Teknik Sumber Daya Air. Erlanga, Jakarta.

Mindawati, N. dan T. Tiryana. 2002. Pertumbuhan Khaya Anthotecha di Jawa Barat. (Growth of Khaya anthotheca in West Java). Buletin Penelitian Hutan, 632:47-58.

Plaster, E.J. 2003. Soil Science and Management $4^{\text {th }}$ Edition. Thomson Learning, New York.

Priyono, N.S. dan S. Sadhardjo. 2002. Hutan pinus dan hasil air. ekstraksi hasil- hasil penelitian tentang hutan pinus terhadap erosi dan tata air. Pusat Pengembangan Sumber Daya Hutan Perhutani, Cepu.

[Puslittanak]. Pusat Penelitian Tanah dan Agroklimat. 1966. Peta Tanah Tinjau Provinsi Jawa Barat. Bogor.

Rahim, S.E. 2003. Pengendalian Erosi Tanah: dalam Rangka Pelestarian Lingkungan Hidup. PT Bumi Aksara, Jakarta.

Sunarti, N. Sinukaban, B. Sanim dan S.D. Tarigan. 2008. Konversi hutan menjadi lahan usahatani karet dan Kelapa Sawit serta pengaruhnya terhadap aliran permukaan dan erosi tanah di DAS Batang Pelepat. Journal of Tropical Soils, 13:253-260.

Tanner, C.B. 1981. Transpiration efficiency of potato. J. Agron., 73:59-64. Doi: 10.2134/agronj1981.00021962007300010014x.

Tarigan, S.D. and S. Widyaliza. 2015. Expansion of oil palm plantations and forest cover changes in Bungo and Merangin Districts, Jambi Province, Indonesia. Procedia Environmental Sciences, 24:199-205

Tarigan, S.D. 2016. Land cover change and its impact on flooding frequency of Batanghari Watershed, Jambi Province, Indonesia. Procedia Environmental Sciences, 33:386-392.

Tarigan, S.D., K. Wiegand, C. Dislich, B. Slamet, J. Heinonen and K. Meyer. 2016. Mitigation options for improving the ecosystem function of water flow regulation in a watershed with rapid expansion of oil palm plantations. Sustainability of Water Quality and Ecology, 8:4-13. http://dx.doi.org/10.1016/j.swaqe.2016.05.001

[USDA] United States Departement od Agriculture. 2009. National Engineering Handbook, Part 630 Hydrology Chapter, Hydrology Soil Groups. United State of Agriculture Natural Resource Conservation Service, Washington DC. 